UDK: 655.3.022:004.9

DOI: https://doi.org/10.24867/03EF01Djurdjevic

\title{
UPOREĐIVANJE BOJA HDR 250 I HDR 230 NA RAZLIČITIM PODLOGAMA ŠTAMPANIM NA GRAFIČKOM SISTEMU HP FB 11000
}

\section{COMPARING INKS HDR 250 WITH HDR 230 ON VARIOUS SUBSTRATES USING HP FB 11000 PRINTING MACHINE}

\author{
Milana Đurđević, Nemanja Kašiković, Jelena Vasić, Fakultet tehničkih nauka, Novi Sad
}

\begin{abstract}
Oblast - GRAFIČKO INŽENJERSTVO I DIZAJN
Kratak sadržaj - Rad obuhvata ispitivanje otpornosti UV boje odštampane na različitim podlogama tehnikom ink jet štampe kao i postojanost boja na njihovoj površini usled dejstva trljanja. Štampa je rađena na različitim materijalima koji se najčešće koriste pri štampi ovom tehnikom, a to su papir, karton, akyplac, printolyte, forex i pleksiglas
\end{abstract}

Ključne reči: digitalna štampa, ink jet, trljanje, razlika u boji, optička gustina

\begin{abstract}
This paper involves testing the UV color resistance printed on different substrates by the ink jet printing technique as well as the durability of the application on their surface due to the effects of rubbing. The printing was done on various substrats that are most commonly used in printing on this technique, such as paper, cardboard, akyplac, printolyte, forex and plexyglass.
\end{abstract}

Keywords: Digital printing, ink jet, color difference, rubbing, optical density

\section{UVOD}

Trenutno najpopularnije metode digitalne štampe su ink jet i elektrofotografija. Te tehnike štampe koriste različite tipove boja koje omogućavaju štampu na različitim štamparskim podlogama (papir, foto papir, platno, staklo, platika, metal i dr.). U nekim od navedenih podloga dolazi do upijanja boje čime je ostvaren osnovni preduslov kao i kod procesa sušenja konvencionalnih tipova boja. Neke boje će na površini otiska stvarati samo tanak sloj koji se mora dodatno fiksirati (zagrevanje praskaštog tonera $u$ elektrofotografiji ili procesom UV sušenja u ink jet-u). U odnosu na tradicionalne štamparske metode, digitalna štampa ima višu cenu po štampanoj stranici, ali u tu cenu ne uračunava se cena izrade štamparske forme jer se ona kao takva fizički ne izrađuje. Zbog toga je niža cena otiska, ali samo za male tiraže [1].

Štampom ink jet tehnologije moguće je naneti boju na gotovo svaku podlogu za štampu [2]. Međutim, kako je reč o tečnim bojama, one ne mogu jednako prijanjati na sve podloge. Zbog toga se u praksi primenjuju različite formulacije boja u ink jet-u koje će se nanositi u različitim

\section{NAPOMENA:}

Ovaj rad proistekao je iz master rada čiji mentor je bio dr Nemanja Kašiković, vanr. prof. nanosima i fiksirati raznim metodama sušenja. Zbog toga se $u$ ink jet štampi postiže i različiti kvalitet reprodukcije koji će uticati na njegovu krajnju upotrebu. Drugim rečima razlika u sastavu i debljini nanosa boje za ink jet uzrokuje $\mathrm{i}$ različitu trajnost i postojanost. Tako se pod pojmom trajnosti podrazumeva otpornost otiska na otiranje, mrljanje i otpornost na vlagu, a postojanost je funkcionalna upotreba otiska (koliko će dugo otisci trajati pod spoljašnjim i unutrašnjim uslovima a da se tonski ne promene) [3].

Upravo zbog toga je i postavljen cilj ovog rada, a to je da se ispita otpornost UV UV boje odštampane na različitim podlogama tehnikom ink jet štampe kao i postojanost boja na njihovoj površini usled dejstva trljanja.

\section{METOD IZVOĐENJA EKSPERIMENTA}

Ispitivanje i procena razlike u reprodukciji izvršena je za dve iste ink jet štamparske mašine HP Scitex FB 11000. Ova mašina koristi za štampu UV boje. Razlika koja je ispitivana je upravo boja, jedna mašina koristi boje HDR 230 HP Scitex koje imaju bolje karakteristike kada se koriste za papir dok druga mašina koristi boje HDR 250 HP Scitex koje su univerzalne za sve podloge. Kao podloga za štampu odabrani su sledeći materijali za štampu velikih formata, a to su: papir, karton, akyplac, printolyte, forex i pleksiglas.

Prilikom merenja ispitani su parametri optičke gustine, relativne spektralne refleksije, Lab vrednosti koordinata boje, razlike otisaka u boji, kao i otpornost na trljanje. Zbog ograničenosti prostorom u nastavku je predstavljeno kako uticaj trljanja utiče na vrednosti optičke gustine.

Za potrebe eksperimenta korišćena su dva seta uzoraka. Prvi uzorci su dobijeni u štampariji NS Plakat u Novom Sadu, na kojima je identična test karta (slika 1) odštampana pomoću jedne mašine za štampu, korišćenjem iste vrste boja. Drugi set je odštampan u štampariji Print Grupa u Zagrebu, na isti način kao i u Novom Sadu, sa tim što identična mašina koristi drugu vrstu boje.

Prilikom trljanja probnih uzoraka, za svaku podlogu određena su tri prelomna trenutka, pri kojima dolazi do vidljivih promena na otisku, kako bi se dobijeni rezultati mogli sortirati i kako bi se mogla izvršiti njihova komparacija i diskusija.

Pomoću spektrofotometrijskog uređaja SpectroDens (merna geometrija $0 / 45^{\circ}$; standardni posmatrač $2^{\circ}$; 
standardno osvetljenje D50; tolerancija greške 0,3) (slika 2) praćene su promene na svakom uzorku. $\mathrm{Na}$ svakoj podlozi, odnosno na svakom uzorku vršeno je 3 merenja po svakoj boji na unapred definisanim mestima i dobijeni su rezultati optičke gustine za analizirane uzorke.
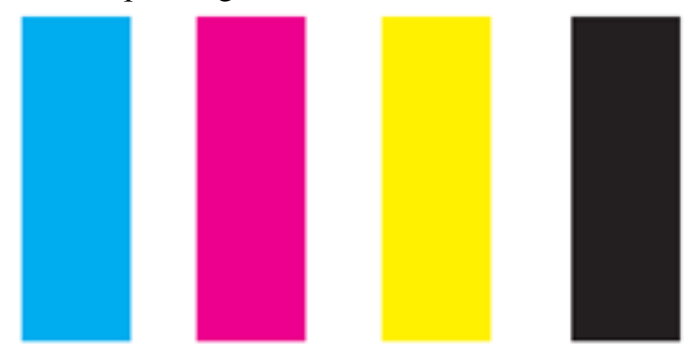

Slika 1. Prikaz test forme

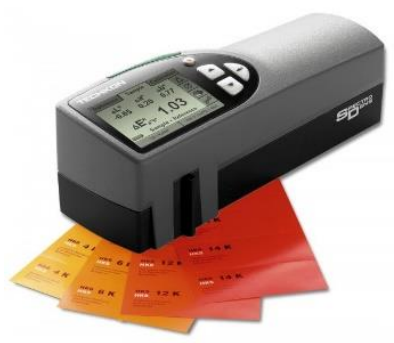

\section{Slika 2. Prikaz TECHKON Spectro Dens uređaja}

Za potrebe trljanja uzoraka korišćen je uređaj Testex TF411. U okviru ovog eksperimenta primenjena je metoda suvog trljanja.

\section{REZULTATI I DISKUSIJA}

Test forme koje su štampane su sadržale četiri polja koja su veličine $12 \times 4 \mathrm{~cm}$ sa $100 \%$ tonskom vrednošću svake od procesnih boja (cijan, magenta, žuta i crna). Prvi set uzoraka koji je štampan HDR 230 HP Scitex bojama u daljem tekstu će biti oslovljen kao P uzorci, dok će drugi set koji je ištampan HDR 250 HP Scitex bojama biti oslovljen kao U uzorci.

Kao što je već pomenuto uzorci su testirani uz pomoć Testex TF411 uređaja za trljanje materijala, u tri ciklusa sa određenim brojem trljanja $u$ zavisnosti od podloge. Broj trljanja je utvrđen nakon prve vidljive promene tokom prvog ciklusa trljanja.

Merenja su ispod svakog grafika i u svakoj tabeli obeležena rimskim brojevima. (I, II, III, IV).

\subsection{Optička gustina}

Merenje vrednosti optičke gustine na svim uzorcima vršeno je tri puta, na svakoj od četiri procesne boje pre prvog i nakon svakog završenog ciklusa trljanja. Kalibracija uređaja vršena je na podlozi na kojoj se vrši merenje.

\subsubsection{P uzorci}

Može se uočiti na slici 3 da nakon svakog ciklusa trljanja optička gustina opada, kao što je i očekivano. Najveća vrednost optičke gustine pre trljanja izmerena je na uzorku P2, dok je najmanja vrednost izmerena na uzorku P6. Nakon trećeg ciklusa trljanja najveća vrednost optičke gustine izmerena je na uzorku P5, dok je na uzorku P4 izmerena najmanja vrednost.

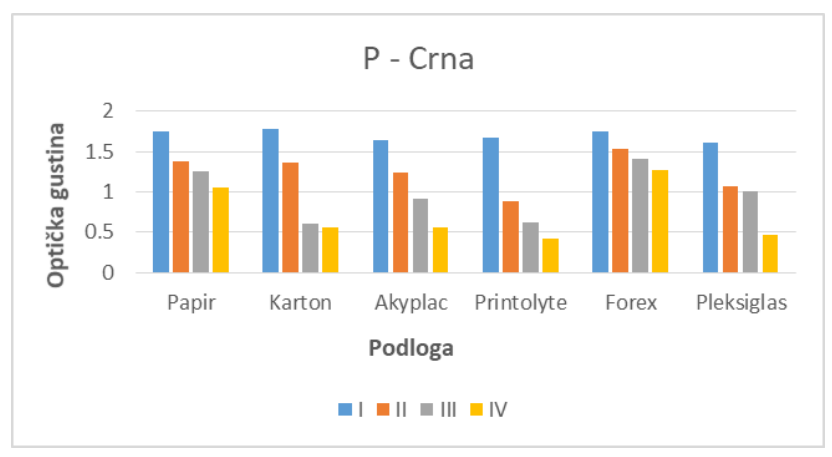

Slika 3. Prikaz srednjih vrednosti optičke gustine za crnu

I na slici 4 se može uočiti da optička gustina ima opadajući trend. Najveća vrednost optičke gustine pre trljanja izmerena je na uzorku P2, dok je najmanja vrednost izmerena na uzorku P6. Nakon trećeg ciklusa trljanja najveća vrednost optičke gustine izmerena je na uzorku P2, dok je na uzorku P6 izmerena najmanja vrednost. U ovom slučaju, može se uočiti da se nakon drugog ciklusa trljanja vrednost optičke gustine povećava na uzorcima P1, P3 i P5.

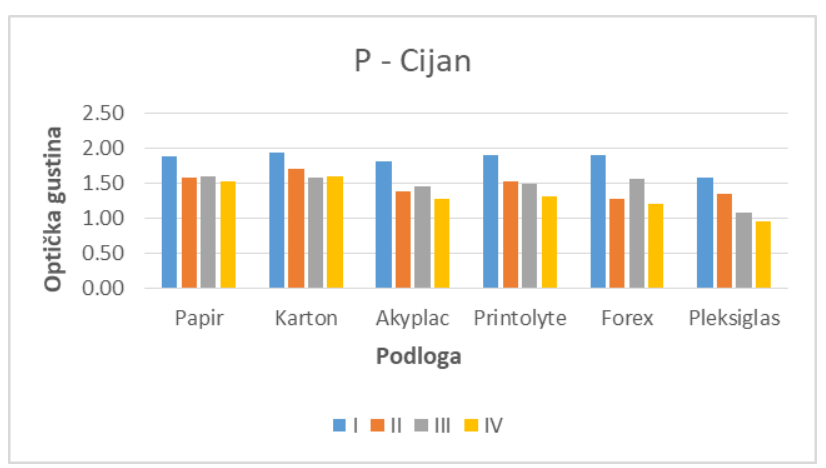

Slika 4. Prikaz srednjih vrednosti optičke gustine za cijan

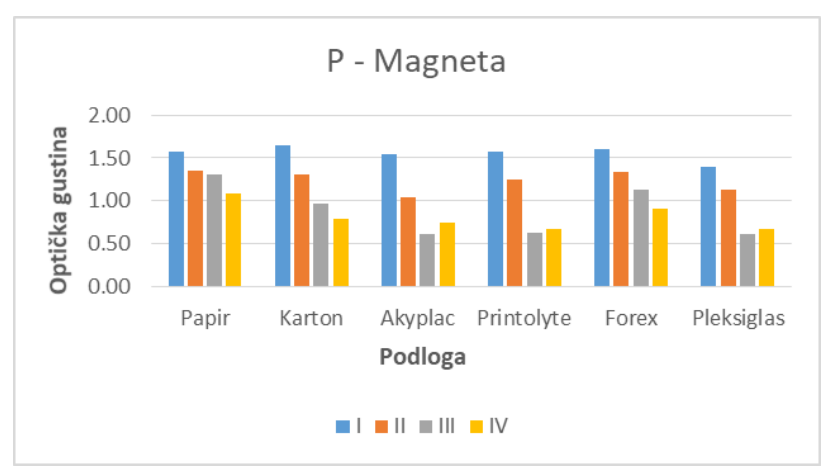

Slika 5. Prikaz srednjih vrednosti optičke gustine za magentu

Može se uočiti i sa slike 5 da optička gustina opada prilikom izlaganja procesu trljanja. Najveća vrednost optičke gustine pre trljanja izmerena je na uzorku P2, dok je najmanja vrednost izmerena na uzorku P6. Nakon trećeg ciklusa trljanja najveća vrednost optičke gustine izmerena je na uzorku P1, dok je na uzorcima P4 i P6 izmerena najmanja vrednost. U ovom slučaju, može se uočiti da se nakon trećeg ciklusa trljanja vrednost optičke gustine povećava na uzorcima P3, P4 i P6.

Isti trend ponašanja je zabeležen i kod uzoraka odštamapnih žutom bojom, pa se može se uočiti na slici 6 da optička gustina opada nakon svakog ciklusa trljanja. 
Najveća vrednost optičke gustine pre trljanja izmerena je na uzorku P5, dok je najmanja vrednost izmerena na uzorku P6. Nakon četvrtog merenja najveća vrednost optičke gustine izmerena je na uzorku P5, dok je na uzorku P3 izmerena najmanja vrednost.

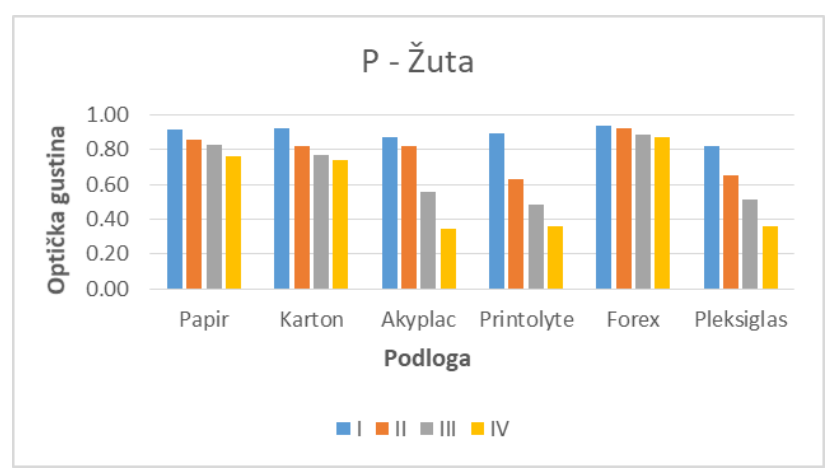

Slika 6. Prikaz srednjih vrednosti optičke gustine za žutu

$\mathrm{Na}$ osnovu dobijenih rezultata, može se zaključiti da su u slučaju štampe sa HP HDR230 Scitex inks bojama najmanje razlike u optičkoj gustini nakon trećeg ciklusa trljanja uočene kod žute procesne boje na svim podlogama, dok su najveće razlike uočene kod crne (za uzorke P1, P2, P3, P4 i P6) i cijan procesne boje (za uzorak P5).

\subsubsection{U uzorci}

Sa slike 7 se uočava da nakon svakog ciklusa trljanja optička gustina opada, kao što je i očekivano. Najveća vrednost optičke gustine pre trljanja izmerena je na uzorku U5, dok je najmanja vrednost izmerena na uzorku U6. Nakon trećeg ciklusa trljanja najveća vrednost optičke gustine izmerena je na uzorku U1, dok je na uzorku U6 izmerena najmanja vrednost.

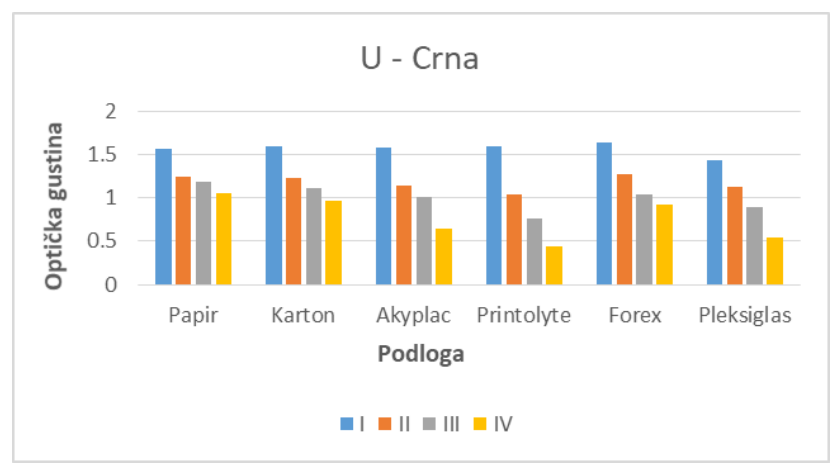

Slika 7. Prikaz srednjih vrednosti optičke gustine za crnu

Može se uočiti na slici 8 da nakon svakog ciklusa trljanja optička gustina opada.

Najveća vrednost optičke gustine pre trljanja izmerena je na uzorku U2, dok je najmanja vrednost izmerena na uzorku U6.

Nakon trećeg ciklusa trljanja najveća vrednost optičke gustine izmerena je na uzorku U1, dok je na uzorku U4 izmerena najmanja vrednost.

Optička gustina uzoraka odštampanih magenta bojom, kao i kod prethodnih uzoraka opada, što je i prikazano na slici 9. Najveća vrednost optičke gustine pre trljanja izmerena je na uzorku U2, dok je najmanja vrednost izmerena na uzorku U6.
Nakon trećeg ciklusa trljanja najveća vrednost optičke gustine izmerena je na uzorku U1, dok je na uzorcima U3 izmerena najmanja vrednost. U ovom slučaju, može se uočiti da se nakon trećeg ciklusa trljanja vrednost optičke gustine povećava na uzorcima U1 i U5.

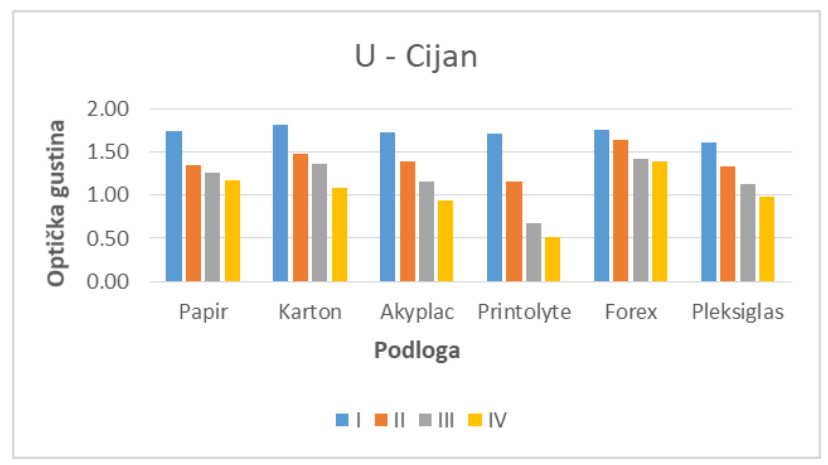

Slika 8. Prikaz srednjih vrednosti optičke gustine za cijan

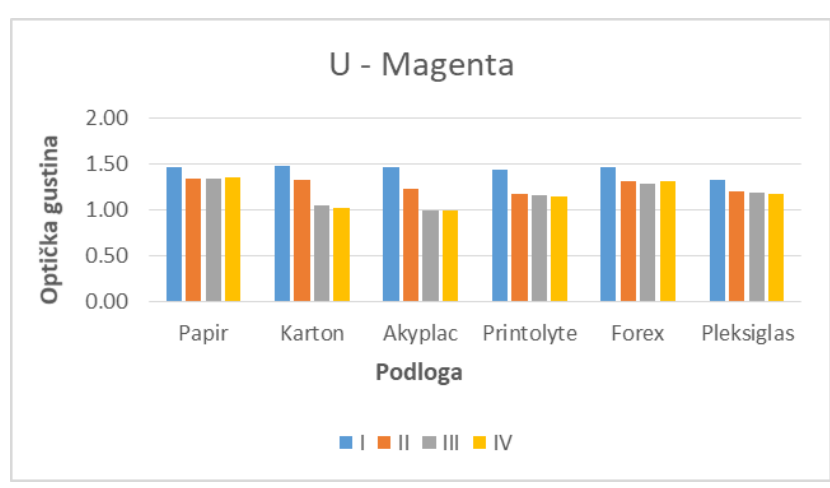

Slika 9. Prikaz srednjih vrednosti optičke gustine za magentu

Može se uočiti na slici 10 da optička gustina opada nakon svakog ciklusa trljanja i kod uzoraka odštampanih žutom bojom.

Najveća vrednost optičke gustine pre trljanja izmerena je na uzorku U1, dok je najmanja vrednost izmerena na uzorku U6.

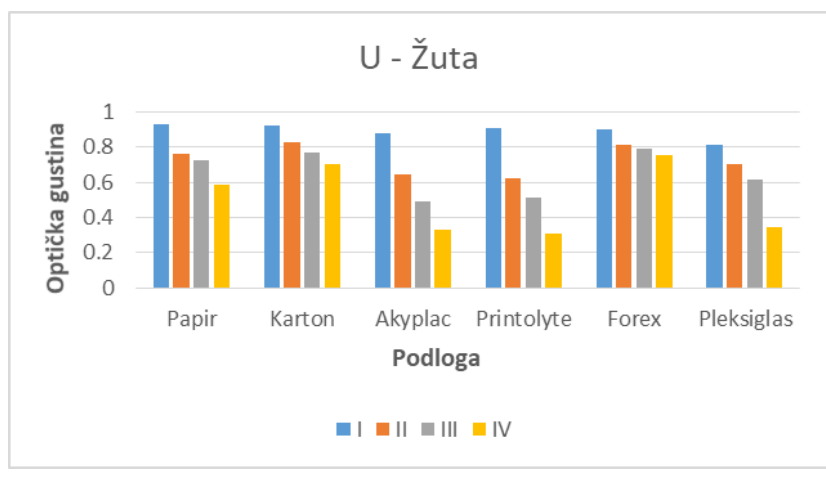

Slika 10. Prikaz srednjih vrednosti optičke gustine za žutu

$\mathrm{Na}$ osnovu dobijenih rezultata, može se zaključiti da su u slučaju štampe sa HP HDR250

Scitex inks bojama najmanje razlike u optičkoj gustini nakon trećeg ciklusa trljanja uočene kod magenta (za uzorke U1, U3, U4 i U6) i žute procesne boje (za uzorke U2 i U5), dok su najveće razlike uočene kod crne (za uzorke U3 - U6) i cijan procesne boje (za uzorke U1 i $\mathrm{U} 2$ ). 


\section{ZAKLJUČAK}

Nakon završenih ispitivanja promene kvaliteta odštampane boje nakon trljanja u zavisnosti od podloge na kojoj je izvršena štampa koje čine jedan set, i upoređivanje rezultata sa drugim setom dobijeni rezultati dovode do zaključka da se delovanjem trljanja na površinu narušava kvalitet uzorka.

Sa povećanjem broja ciklusa trljanja, rastu i promene na uzorcima, tako da kod nekih podloga dolazi i do kompletnog skidanja boje sa podloge.

Logično, najveće razlike uočljive su između referentnog uzorka, odnosno uzorka u početnom stanju i uzorka nakon završetka trećeg ciklusa trljanja.

Rezultati su pokazali da su se na različitim podlogama, sa aspekta dobijenih vrednosti razlike u boji, bolje pokazale HP HDR250 Scitex boje, pri čemu se mora istaći da se za papirne i kartonske podloge ipak bolji rezultati postižu korišćenjem HP HDR230 Scitex boja što je u skladu sa specifikacijama istih.

U okviru daljih pravca istraživanja moglo bi se osvrnuti na broj trljanja, koji bi mogao da bude uniforman za svaku podlogu u toku jednog ciklusa.

\section{LITERATURA}

[1] Novaković D., Kašiković N. (2013), Digitalna štampa, FTN izdavaštvo, Novi Sad.

[2] Kipphan, H., 2001. Handbook of Print Media, Berlin: Springer-Verlag Berlin Heidelberg

[3] Majnarić, I. (2015). Osnove digitalnog tiska. Zagreb, Sveučilište u Zagrebu, Grafički fakultet

\section{Adresa za kontakt:}

MSc Milana Đurđević, milanadju@yahoo.com

Dr Nemanja Kašiković, knemanja@uns.ac.rs

MSc Jelena Vasić, jelena.vasic@uns.ac.rs 